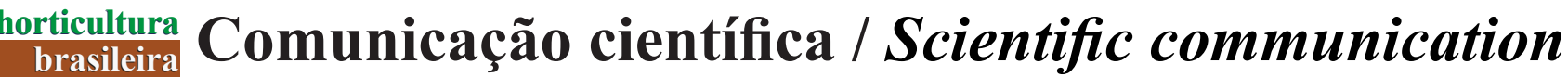

FISCHER, SZ; BARBIERI, RL; PEIL, RMN; STUMPF, ERT; NEITZKE, RS; VASCONCELOS, CS; TREPTOW, RO. 2016. Cultivo e uso de variedades crioulas de abóboras ornamentais no Rio Grande do Sul. Horticultura Brasileira 34: 398-404. DOI - http://dx.doi.org/10.1590/S0102-05362016003015

\section{Cultivo e uso de variedades crioulas de abóboras ornamentais no Rio Grande do Sul}

\author{
Síntia Z Fischer'후 Rosa L Barbieri²; Roberta MN Peil ${ }^{3}$; Elisabeth RT Stumpf ${ }^{1}$; Raquel S Neitzke ${ }^{4}$; Carla S \\ Vasconcelos $^{3}$; Rosa O Treptow ${ }^{2}$ \\ ${ }^{1}$ Instituto Federal Sul-Rio-Grandense (IFSul), Pelotas-RS, Brasil; sintiafischer@gmail.com; elizabethstumpf@gmail.com; ${ }^{2}$ Embrapa \\ Clima Temperado, Pelotas-RS, Brasil; rosa.barbieri@embrapa.br; rotreptow@hotmail.com; ${ }^{3}$ Universidade Federal de Pelotas (UFPel), \\ Pelotas-RS, Brasil; rmpeil@ufpel.edu.br; carla_sigales@hotmail.com; ${ }^{4}$ Prefeitura Municipal de Arroio do Padre, Arroio do Padre-RS, \\ Brasil; raquelsilviana@gmail.com
}

\section{RESUMO}

No Brasil, são cultivadas variedades crioulas de diversas espécies de cucurbitáceas. A maior diversidade genética de Cucurbita em cultivo parece ser encontrada no Rio Grande do Sul, onde os agricultores praticam e detêm o conhecimento popular mediante práticas dinâmicas de guardar e trocar estas sementes, sendo que muitas destas variedades apresentam potencial para uso ornamental. Assim, este trabalho foi desenvolvido com o objetivo de resgatar o conhecimento popular associado ao uso e cultivo de variedades crioulas de abóboras ornamentais no Rio Grande do Sul. Para isso, foram realizadas entrevistas com agricultores doadores de sementes de variedades crioulas do Banco Ativo de Germoplasma (BAG) de Cucurbitáceas da Embrapa Clima Temperado. Nas entrevistas, foi utilizado um questionário semiestruturado, com dados de identificação do entrevistado (iniciais do nome, idade, sexo, profissão, etnia e local) e questões norteadoras relativas ao conhecimento sobre abóboras ornamentais (histórico de cultivo na família, procedência da semente, nome popular atribuído, razões para manter o cultivo, época de plantio e colheita, critérios de seleção dos frutos, formas de utilização, local e manejo do cultivo, e formas de retirada e armazenamento das sementes). Foram entrevistados 12 doadores do BAG e, através destes, foram localizadas outras nove pessoas que também cultivam variedades crioulas de abóboras ornamentais, sendo possível o incremento de três novos acessos para o BAG. Foi possível concluir que há uma relação afetiva dos guardiões com suas seleções e que existe uma grande diversidade de variedades crioulas de abóboras ornamentais mantidas por agricultores familiares do Sul do Rio Grande do Sul.

Palavras-chave: Cucurbita, Cucurbitaceae, agricultura familiar, recursos genéticos, patrimônio cultural.

\begin{abstract}
Production and use of ornamental pumpkin landraces in the Rio Grande do Sul State, Brazil

Landraces of several cucurbit species are cultivated in Brazil. The greatest genetic diversity of cultivated Cucurbita seems to be found in Rio Grande do Sul State, where farmers have the knowledge and practice to store and exchange these seeds. Many of these varieties have potential for ornamental use. This research was developed to rescue the popular knowledge associated with the use and cultivation of landraces of ornamental pumpkins in Rio Grande do Sul State, Brazil. Farmers that donor landraces seeds to the Cucurbitaceae Active Germplasm Bank of Embrapa Temperate Agriculture were interviewed. A semi-structured questionnaire was used, with respondent identification (name, age, profession, gender, ethnicity and address) and guiding questions relating to knowledge about ornamental pumpkins (history of cultivation in the family, origin of the seed, popular name assigned, reasons to keep growing, planting time and harvest, the fruit selection criteria, ways to use, location and crop management, and ways of removing and storing seeds). We interviewed 12 farmers who donate the seeds for the Bank and, through them, nine other growers of ornamental pumpkin landraces were identified, which added three new accessions to the Bank. In conclusion, a relationship between the selections and their guardians was observed and a wide diversity of ornamental pumpkin landraces maintained by farmers in southern Rio Grande do Sul State was reported.
\end{abstract}

Keywords: Cucurbita, Cucurbitaceae, family farming, genetic resources, genetic heritage.

(Recebido para publicação em 9 de junho de 2015; aceito em 1 de março de 2016)

(Received on June 9, 2015; accepted on March 1, 2016)

\begin{abstract}
$\mathrm{A}$ s abóboras (Cucurbita sp.), pertencentes à família Cucurbitaceae, são originárias das Américas e faziam parte da base alimentar da civilização Olmeca, posteriormente incorporada pelas culturas Asteca, Inca e Maia. As espécies domesticadas de Cucurbita são provavelmente algumas das plan-
\end{abstract}

tas mais antigas a serem cultivadas na América (Ferreira, 2008). Após a descoberta do Novo Mundo, as abóboras foram levadas para a Europa (Paris et al., 2006) onde, em um contexto social e cultural diferente, ganharam novas dimensões culturais e novos usos, como o ornamental (Hillier, 1996, 2001).
Atualmente seu cultivo é amplamente difundido em todo o mundo, sendo grande parte da produção realizada em pequenas propriedades, para subsistência ou destinada aos mercados locais (Nuez et al., 2000).

No Brasil são cultivadas variedades crioulas de diversas espécies de 
cucurbitáceas. As variedades crioulas são aquelas desenvolvidas, por meio da seleção de plantas, pelos próprios agricultores ao longo do tempo, cujas sementes são passadas de geração a geração e também trocadas entre vizinhos e parentes. No processo de colonização do território brasileiro, cada grupo étnico estabelecido carregava consigo suas próprias sementes, dentre elas, as de abóboras, levando também o conhecimento relacionado ao plantio, manejo, colheita e armazenamento. Mais do que patrimônio genético, estas variedades crioulas fazem parte, portanto, de uma manifestação cultural, que inclui desde o nome que a elas é atribuído, até seu uso (Barbieri, 2012).

A maior diversidade genética de Cucurbita em cultivo parece ser encontrada na Região Sul, em particular no Rio Grande do Sul, onde os agricultores praticam e detêm o conhecimento popular mediante práticas dinâmicas de guardar e trocar estas sementes. Desta forma, contribuem tanto para a conservação da diversidade genética como da cultural (Heiden et al., 2007).

No entanto, muitas vezes os agricultores se veem forçados a abandonar o cultivo tradicional, em função da pressão de uma agricultura tida como moderna, que resulta no rompimento com suas tradições e conhecimentos, substituindo estes por tecnologias genéricas e, em geral, importadas. Neste tipo de cultivo, as variedades crioulas são substituídas por variedades comerciais, principalmente híbridos, em busca de maior rentabilidade (Faleiro et al., 2008).

Apesar de muitos recursos genéticos terem sido perdidos nos últimos anos, ainda há muita diversidade de abóboras a ser coletada no Sul do Brasil. A fim de conservar estes recursos genéticos, a Embrapa Clima Temperado implantou em 2002, o Banco Ativo de Germoplasma de Cucurbitáceas do Sul do Brasil (Barbieri et al., 2006), que conta, atualmente, com cerca de 534 acessos de abóboras, a maior parte doada por agricultores do Rio Grande do Sul, de Santa Catarina e do Paraná.

Considerando que o Sul do Brasil apresenta esta grande diversidade de variedades crioulas de abóboras, muitas destas com potencial de uso ornamental, atividades de resgate do conhecimento tradicional assumem fundamental importância para que a cultura popular associada a estas variedades não se perca e, também, para otimizar o uso imediato desses recursos. Sendo assim, a pesquisa etnobotânica pode auxiliar no resgate deste conhecimento, pois visa recuperar e sistematizar as tradições. A etnobotânica é o estudo do conhecimento e das conceituações desenvolvidas por qualquer sociedade a respeito do mundo vegetal, englobando tanto a maneira como o grupo social classifica as plantas, como os usos que dá a elas (Amorozo, 1996).

As pesquisas etnobotânicas ainda são bastante focadas em sociedades indígenas e plantas medicinais, mas o estudo etnobotânico em sociedades agrícolas, em comunidades locais, pode auxiliar na exploração de recursos genéticos para outras finalidades, servindo de mediadora entre o conhecimento popular e o científico. Begossi et al. (2002) observam que a pesquisa etnobotânica pode contribuir para o desenvolvimento planejado da região onde os dados foram coletados. A intensificação da pesquisa em etnobotânica leva ao aumento do conhecimento associado a diferentes plantas, podendo servir como instrumento para delinear estratégias de uso e conservação das espécies e seus usos potenciais (Ming et al., 2000).

Assim, este trabalho foi desenvolvido com o objetivo de resgatar o conhecimento popular associado ao uso e cultivo de variedades crioulas de abóboras ornamentais no Rio Grande do Sul.

\section{MATERIAL E MÉTODOS}

Com base nos dados de passaporte dos acessos doados ao Banco Ativo de Germoplasma de Cucurbitáceas da Embrapa Clima Temperado, foi realizada uma busca por pessoas que atuam como guardiãs de sementes de variedades crioulas de abóboras ornamentais. De março de 2009 a junho de 2010 foram realizadas visitas às propriedades das pessoas identificadas como doadoras de variedades crioulas ao banco de germoplasma.

$\mathrm{Na}$ visita, após apresentação do objetivo da pesquisa, foi realizada uma entrevista com o responsável pelo cultivo da variedade crioula. Paralelamente, para localizar mais pessoas que atuam como guardiãs de sementes de variedades crioulas de abóboras ornamentais, foi utilizada a metodologia bola de neve (Bailey, 1994), em que os entrevistados indicaram outras pessoas que também cultivavam abóboras ornamentais.

Para as entrevistas, foi utilizado um questionário semiestruturado com questões norteadoras, em conformidade com a metodologia de Amorozo et al. (2002), no qual os temas foram abordados sem uma ordem específica, de acordo com o ritmo da conversa (Nichols, 1991) e o entrevistado pôde discorrer livremente acerca do assunto. O questionário incluiu dados de identificação do entrevistado (nome, idade, profissão, sexo, etnia e endereço) e questões relativas ao conhecimento sobre abóboras ornamentais (histórico de cultivo na família, procedência da semente, nome popular atribuído, razões para manter o cultivo, época de plantio e colheita, critérios de seleção dos frutos, formas de utilização, local e manejo do cultivo, formas de retirada e armazenamento das sementes).

Foram utilizados como instrumentos para a coleta dos dados o diário de campo, a observação direta e o registro fotográfico, previamente autorizado pelos informantes. Os entrevistados foram identificados pelas letras iniciais do nome.

\section{RESULTADOS E DISCUSSÃO}

Foram identificados quinze doadores de sementes de variedades crioulas de abóboras ornamentais nos dados de passaporte do Banco Ativo de Germoplasma de Cucurbitáceas da Embrapa Clima Temperado. Destes, doze foram localizados e entrevistados, e através da indicação dos primeiros entrevistados foram localizadas mais nove pessoas que também cultivavam variedades crioulas de abóboras ornamentais, sendo estes também entrevistados. Por meio destas indicações foi possível o incremento de três novas variedades de 
Tabela 1. Identificação dos entrevistados no levantamento etnográfico relacionado a variedades crioulas de abóboras ornamentais (identification of people interviewed in ethnographic survey related to ornamental pumpkin landraces). Pelotas, Embrapa Clima Temperado, 2010.

\begin{tabular}{|c|c|c|c|c|c|c|c|c|}
\hline $\begin{array}{l}\text { Iniciais } \\
\text { do nome }\end{array}$ & Idade & Sexo & Profissão & Etnia & Local & $\begin{array}{l}\text { Espécie de } \\
\text { abóbora } \\
\text { ornamental } \\
\text { cultivada } \\
\end{array}$ & $\begin{array}{l}\text { Nome popular } \\
\text { atribuído }\end{array}$ & $\begin{array}{c}\text { Forma de } \\
\text { utilização* }\end{array}$ \\
\hline I.F.H. & 58 & $\mathrm{~F}$ & $\begin{array}{l}\text { aposentada } \\
\text { comércio }\end{array}$ & alemã & $\begin{array}{c}\text { Reserva/São } \\
\text { Lourenço do Sul }\end{array}$ & Curcubita pepo & abobrinha & $\begin{array}{c}\text { enfeite na } \\
\text { cozinha }\end{array}$ \\
\hline L.L.Z. & 39 & $\mathrm{~F}$ & $\begin{array}{l}\text { agrônoma/ } \\
\text { agricultora }\end{array}$ & alemã & $\begin{array}{l}\text { Picada das Antas/ } \\
\text { São Lourenço do Sul }\end{array}$ & C. реро & brasileirinha & ornamentação \\
\hline A.S.R. & 60 & $\mathrm{~F}$ & agricultora & alemã & $\begin{array}{l}\text { Espinilho/São } \\
\text { Lourenço do Sul }\end{array}$ & C. maxima & cogumela & ornamentação \\
\hline N.L.F. & 41 & $\mathrm{~F}$ & laboratorista & alemã & $\begin{array}{l}\text { Santa Eulália/ } \\
\text { Pelotas }\end{array}$ & C. реро & $\begin{array}{c}\text { porongo e } \\
\text { moganguinho }\end{array}$ & ornamentação \\
\hline E.W. & 63 & $\mathrm{~F}$ & $\begin{array}{l}\text { agricultora/ } \\
\text { feirista }\end{array}$ & alemã & $\begin{array}{l}\text { Cerrito Alegre/ } \\
\text { Pelotas }\end{array}$ & C. maxima & abóbora alemã & $\begin{array}{l}\text { ornamentação/ } \\
\text { alimentação }\end{array}$ \\
\hline R.H.S.S. & 62 & $\mathrm{~F}$ & agricultora & portuguesa & $\begin{array}{c}\text { Santa Eulália/ } \\
\text { Pelotas }\end{array}$ & C. реро & $\begin{array}{c}\text { redondinha, } \\
\text { bicudinha }\end{array}$ & $\begin{array}{c}\text { decorar a casa/ } \\
\text { pintar depois } \\
\text { de seca }\end{array}$ \\
\hline G. H. & 62 & $\mathrm{~F}$ & agricultora & alemã & Corrientes/Turuçu & C. реро & abobrinha & ornamentação \\
\hline A.B. & 51 & M & agricultor & alemã & Santana/Turuçu & C. реро & - & para doce \\
\hline I.W. & 54 & $\mathrm{~F}$ & agricultora & alemã & $\begin{array}{l}\text { Cerrito Alegre/ } \\
\text { Pelotas }\end{array}$ & С. реро & $\begin{array}{c}\text { abobrinha de coco } \\
\text { e ovo }\end{array}$ & $\begin{array}{c}\text { ornamentação/ } \\
\text { alimentação }\end{array}$ \\
\hline A.S.K. & 73 & $\mathrm{~F}$ & agricultora & alemã & Cascata/Pelotas & C. pepo & estrela/dedo & enfeitar a casa \\
\hline S.H.K. & 45 & $\mathrm{~F}$ & agricultora & alemã & $\begin{array}{l}\text { Rincão da Cruz/ } \\
\text { Pelotas }\end{array}$ & C. реро & abóbora de enfeite & para bonito \\
\hline C.M. & 30 & $\mathrm{~F}$ & $\begin{array}{l}\text { agricultora/ } \\
\text { feirista }\end{array}$ & alemã & $\begin{array}{c}\text { BR 116/São } \\
\text { Lourenço do Sul }\end{array}$ & $\begin{array}{c}\text { C. maxima e } C . \\
\text { pepo }\end{array}$ & abóbora & para bonito \\
\hline D.S. & 47 & $\mathrm{~F}$ & agricultora & alemã & $\begin{array}{l}\text { Picada das Antas/ } \\
\text { São Lourenço do Sul }\end{array}$ & C. реро & abobrinha & ornamentação \\
\hline M.R.K.S. & 55 & $\mathrm{~F}$ & professora & alemã & $\begin{array}{l}\text { Av. dos Pinhais/ } \\
\text { Morro Redondo }\end{array}$ & C. реро & poronguinho & ornamentação \\
\hline L.J. & 60 & $\mathrm{~F}$ & agricultora & alemã & $\begin{array}{l}\text { Picada das Antas/ } \\
\text { São Lourenço do } \\
\text { Sul }\end{array}$ & C. реро & abobrinha de natal & $\begin{array}{c}\text { ornamentação/ } \\
\text { ornamento } \\
\text { para árvore } \\
\text { de Natal/ } \\
\text { alimentação }\end{array}$ \\
\hline E.B.R. & 54 & $\mathrm{~F}$ & agricultora & alemã & $\begin{array}{l}\text { Pinheiros/São } \\
\text { Lourenço do Sul }\end{array}$ & $\begin{array}{c}\text { C. maxima } \mathrm{e} C . \\
\text { pepo }\end{array}$ & $\begin{array}{l}\text { cogumela/ } \\
\text { branquinha }\end{array}$ & $\begin{array}{l}\text { ornamentação/ } \\
\text { alimentação }\end{array}$ \\
\hline N.M. & 60 & M & agricultor & alemã & $\begin{array}{l}\text { Pinheiros/São } \\
\text { Lourenço do Sul }\end{array}$ & $\begin{array}{l}\text { C. maxima } \mathrm{e} \\
\text { C.pepo }\end{array}$ & cogumela/estrela & $\begin{array}{l}\text { ornamentação/ } \\
\text { alimentação }\end{array}$ \\
\hline М.Н.Н. & 60 & $\mathrm{~F}$ & $\begin{array}{l}\text { agricultora/ } \\
\text { feirista }\end{array}$ & alemã & Gama/Pelotas & C. реро & $\begin{array}{c}\text { ornamental ou de } \\
\text { enfeite }\end{array}$ & ornamentação \\
\hline I.D. & 40 & $\mathrm{~F}$ & agricultora & alemã & Aliança/Pelotas & C. реро & chocalho ou ovo & para bonito \\
\hline M.J. & 31 & $\mathrm{~F}$ & agricultora & alemã & Aliança/Pelotas & C. реро & - & $\begin{array}{l}\text { ornamento para } \\
\text { árvore de Natal }\end{array}$ \\
\hline I.R.M. & 30 & $\mathrm{~F}$ & agricultora & alemã & Progresso/Pelotas & C. реро & $\begin{array}{l}\text { brouzean (abobrinha } \\
\text { em pomerano) }\end{array}$ & enfeite \\
\hline
\end{tabular}

*Forma de utilização de acordo com o citado pelos entrevistados (form of use according to the respondents). 
abóboras crioulas ornamentais para o acervo do Banco Ativo de Germoplasma de Cucurbitáceas da Embrapa Clima Temperado. No total, foram realizadas 21 entrevistas com os guardiões de sementes, em suas propriedades, com idades variando entre 30 e 73 anos, sendo 19 mulheres e apenas dois homens (Tabela 1). Os entrevistados residiam na zona rural dos municípios de Pelotas, Morro Redondo, Turuçu e São Lourenço do Sul, no Rio Grande do Sul (Figura 1).

A grande maioria dos entrevistados (20 pessoas) declarou ser descendente de imigrantes alemães, sendo apenas um de origem portuguesa. De fato, o cultivo de determinadas variedades de abóbora está estreitamente relacionado com a etnia, sendo que cada etnia cultiva as variedades que são de seu interesse (Barbieri, 2012). A etnia alemã se carac-

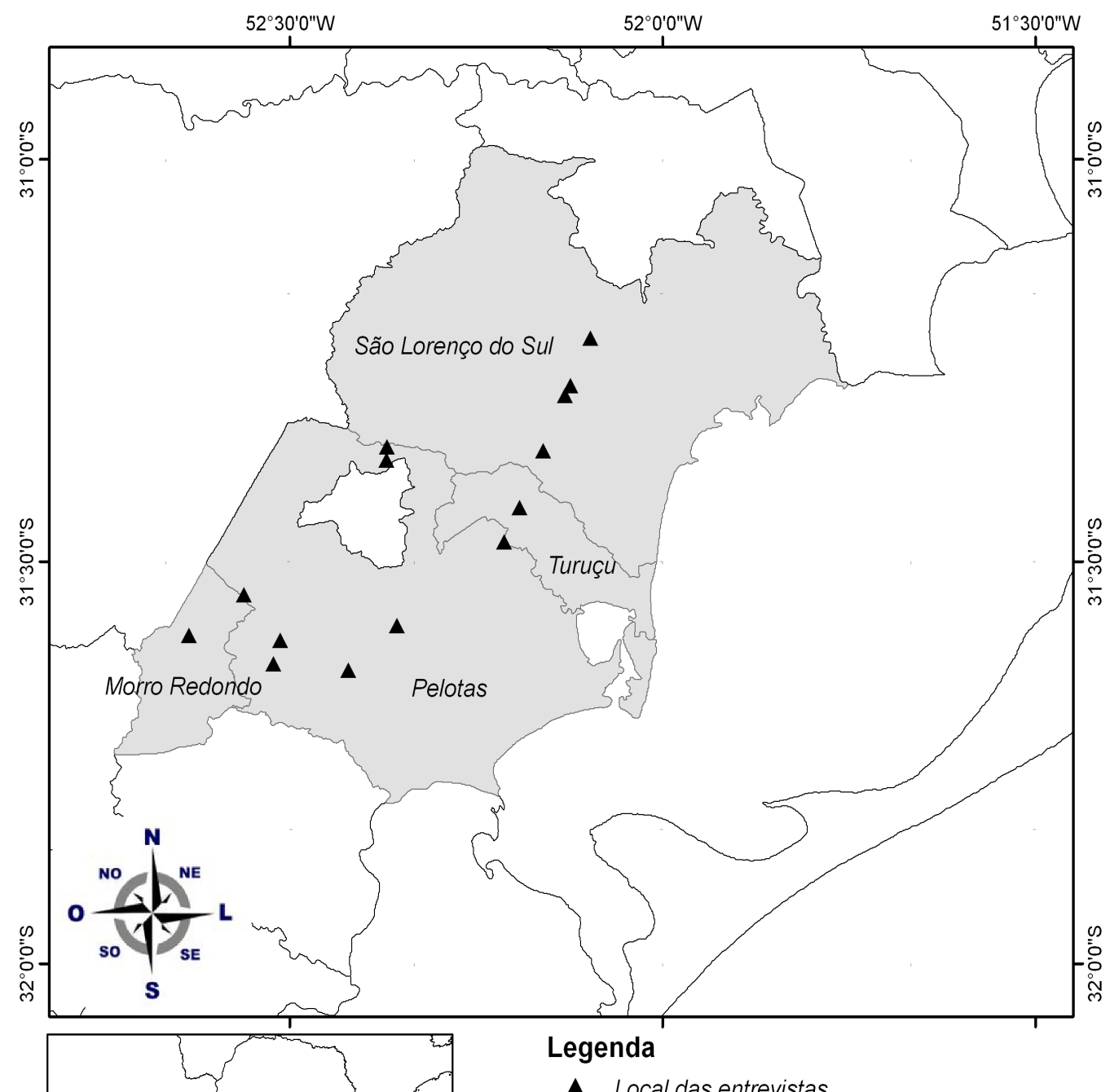

Municípios:

\begin{tabular}{|l|l|}
\hline São Lourenço do Sul: & Pelotas: \\
Pinheiros & Aliança \\
Espinilho & Progresso \\
Reserva & Gama \\
Picada das Antas & Cascata \\
& Rincão da Cruz \\
& Santa Eulália \\
& Cerrito Alegre \\
\hline Turuçu: & Morro Redondo: \\
Santana & Avenida dos Pinhais \\
Corrientes & \\
\hline
\end{tabular}

Figura 1. Mapa com as localidades onde foram realizadas as entrevistas com os guardiões das sementes de variedade crioulas ornamentais para o levantamento etnográfico (map showing locations where the interviews with the keepers of ornamental pumpkins landraces were conducted for the ethnographic survey). Pelotas, Embrapa Clima Temperado, 2010. 

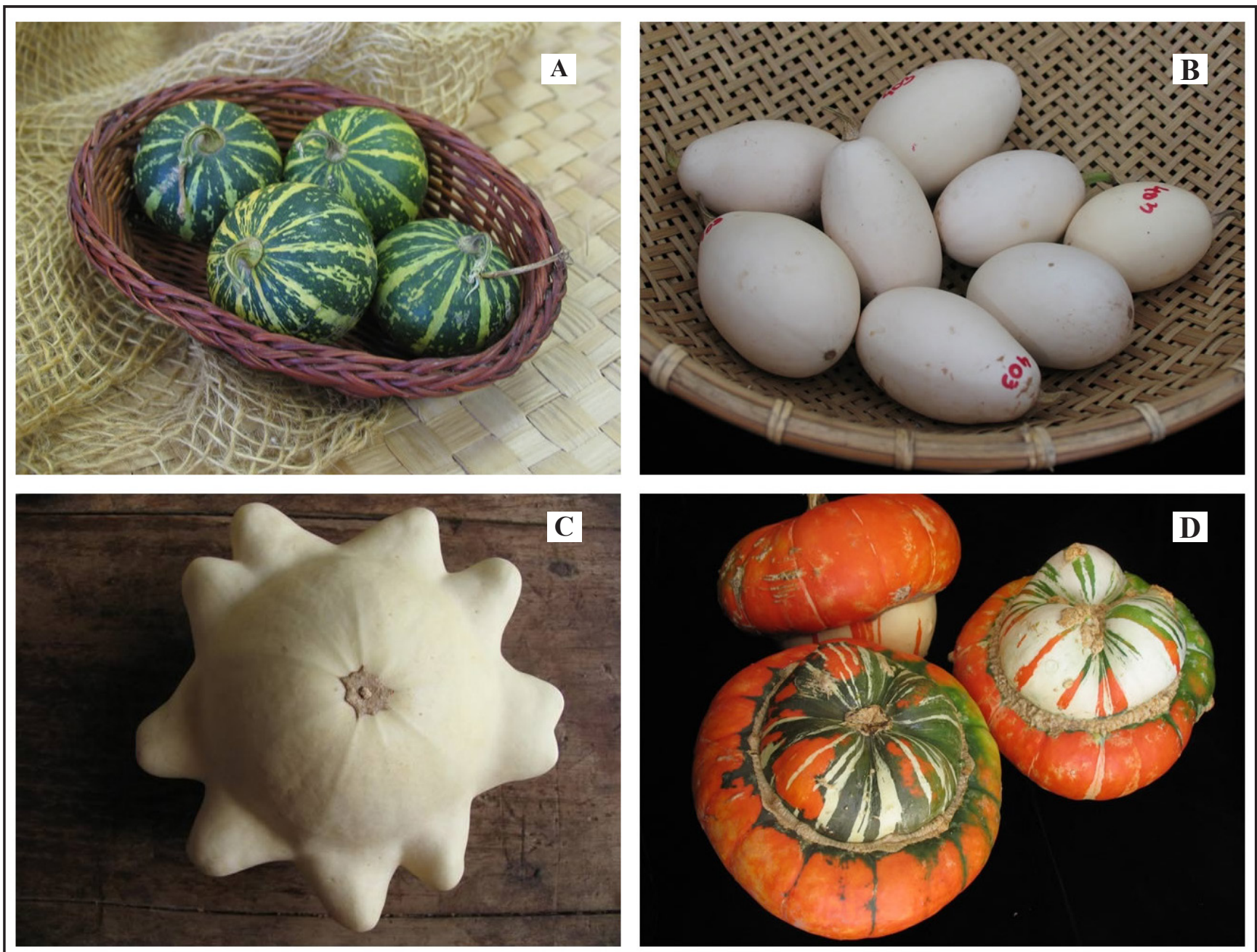

Figura 2. Frutos de variedades crioulas de abóboras ornamentais doadas por agricultores para o Banco Ativo de Germoplasma de Cucurbitáceas da Embrapa Clima Temperado. A) poronguinho (Cucurbita pepo), B) abóbora-ovo (Cucurbita pepo), C) abóbora estrela (Cucurbita pepo), D) abóbora cogumela (Cucurbita maxima) \{fruits of ornamental pumpkins landraces donated by farmers for the Cucurbitaceae Active Germplasm Bank of Embrapa Temperate Agriculture. A) poronguinho (Cucurbita pepo), B) egg pumpkin (Cucurbita pepo), C) star pumpkin (Cucurbita pepo), and D) cogumela pumpkin (Cucurbita maxima)\}. Pelotas, Embrapa Clima Temperado, 2010.

teriza por apreciar plantas ornamentais no entorno das suas residências; assim, é comum e tradicional em zonas de colonização alemã no Sul do Brasil, grandes e coloridos jardins. Desta forma, foi possível observar que os descendentes de alemães continuam mantendo o cultivo de variedades crioulas de abóboras ornamentais, simplesmente pelo prazer da beleza que as mesmas proporcionam, fazendo suas próprias seleções para o cultivo no ano seguinte.

A seleção é feita com base em características morfológicas de fruto, com interesse estético e muito subjetivo e individualizado. Por exemplo, uma das entrevistadas (L.L.Z., 39 anos) prefere os frutos pequenos e, a cada safra, vem selecionando os menores frutos para a retirada das sementes. Como resultado, atualmente, ela cultiva uma variedade crioula que é o acesso com menor tamanho de fruto que faz parte do acervo do Banco Ativo de Germoplasma de Cucurbitáceas da Embrapa Clima Temperado. Com relação aos demais, sete entrevistados declararam que selecionam os maiores frutos, enquanto que um entrevistado informou que seleciona frutos de tamanho médio. Além do tamanho de fruto, outras características são alvo de seleção: cinco entrevistados selecionam os frutos com formatos mais perfeitos de acordo com seus critérios (frutos com formato de cogumelo, pera ou ovo), uma entrevistada seleciona pela presença de um desenho de listras bem definidas na casca do fruto (desenho formado na casca pela cor secundária), duas entrevistadas selecionam os frutos que têm maior durabilidade (mantendo as características estéticas de cor) e duas selecionam pela intensidade da cor da casca do fruto (amarelo e verde). Uma entrevistada citou que guarda a semente dos primeiros frutos colhidos, pois acredita que estas vão ter melhor qualidade para o próximo plantio. Alguns dos entrevistados (sete pessoas) disseram que não realizam nenhum tipo de seleção, escolhem os frutos que consideram bonitos sem ressaltar nenhuma característica específica. Este resultado reforça a afirmação feita por Ramos \& Queiroz (2005), de que a seleção praticada pelos agricultores, nas mais diversas áreas de cultivo de abóbora, 
favorece a ampliação e manutenção da variabilidade genética.

Em relação à forma de retirada e de armazenamento das sementes, a maior parte dos entrevistados (13 pessoas) mantem as sementes dentro dos frutos, algumas (10 pessoas) citaram que quebram os frutos, quando estes perderam a qualidade estética, e jogam os frutos com as sementes nos canteiros, no jardim ou quintal, os outros três simplesmente jogam os frutos inteiros nos canteiros. Aqueles que retiram e armazenam as sementes (oito entrevistados) esperam estas secarem no próprio fruto, para depois retirá-las e guardá-las em garrafas pet ou de vidro, bem vedadas. Uma das entrevistadas comentou que armazena a garrafa pet no freezer. $\mathrm{O}$ plantio é realizado em agosto e setembro. Para o plantio é utilizado apenas um pouco de esterco bovino ao redor da cova de plantio, somente um entrevistado citou o uso de uréia em cobertura. Segundo as palavras de um entrevistado, simplesmente "esquecem" as plantas após a semeadura, realizando a colheita dos frutos uns três meses após o plantio. Esse procedimento é possível devido à rusticidade destas variedades crioulas de abóboras, que não necessitam de um manejo sofisticado durante o cultivo.

O cultivo das abóboras ornamentais é normalmente realizado no quintal ou jardim, perto de alguma árvore ou cerca. Desta forma, durante o cultivo a cerca se transforma em uma cortina verde, com os frutos de abóbora pendurados, oferecendo mais um espetáculo de beleza durante seu desenvolvimento. Após a colheita, os frutos continuam com sua função de embelezar, só que desta vez no ambiente interno das residências. Em geral, o cultivo das abóboras ornamentais é realizado pela mulher da casa, uma vez que na zona rural este espaço do entorno da casa é tipicamente feminino, sendo sua função mantê-lo. De acordo com Amorozo et al. (2002), esta separação de espaços vem desde tempos ancestrais, onde o homem era o responsável por trazer a caça (matas, rios e lavouras eram espaços masculinos) e a mulher tomava conta da casa e do entorno (espaço feminino), sendo este sistema ainda mantido nas sociedades camponesas. Kumar \& Nair (2004) citam também que os quintais (home gardens), possuem longa tradição em países tropicais, onde esses sistemas consistem, geralmente, em uma combinação de árvores, arbustos, trepadeiras, herbáceas, algumas vezes em associação com animais domésticos, crescendo adjacentes à residência, sendo as mulheres responsáveis pela manutenção desse sistema. Apenas dois entrevistados eram homens, os quais, no momento da entrevista, comentaram que não estavam mais fazendo o plantio, e que quando o faziam era para vender para feirantes de hortifrutigranjeiros.

$O$ fato é que as pessoas entrevistadas, que guardam e trocam sementes de variedades de abóboras ornamentais, possuem conhecimento relacionado a este cultivo e mantêm uma relação afetiva com suas sementes. Muitas vezes, essa relação afetiva deriva do fato de que a semente foi recebida como presente de algum parente ou amigo querido, o que foi relatado por 18 entrevistados. Pode-se, neste caso, utilizar o conceito de "plantas de estimação" (Nahoum, 2010), que são aquelas plantas mantidas no entorno das residências, criando um vinculo afetivo. Esses quintais (entorno de residências) podem ser considerados bancos de germoplasma particulares, onde coexistem espécies de plantas silvestres e variedades domesticadas, e são de extrema riqueza em termos de recursos genéticos vegetais. Os resultados do presente trabalho reforçam a constatação de Oakley (2004) e Galluzzi et al. (2009), que enfatizam a função dos quintais domésticos como reservatórios de biodiversidade em comunidades mundo afora.

Dois dos entrevistados relataram que não receberam as sementes como um presente, mas que estas foram compradas na Alemanha há vários anos, sendo, posteriormente, multiplicadas por eles mesmos. Desde então, todos os anos, as plantas são cultivadas na propriedade rural. De modo distinto, outro entrevistado, um feirante de Pelotas, declarou que todo o ano compra sementes de abóboras ornamentais comercializadas por uma empresa de sementes, e que não multiplica suas próprias sementes.

Outro fato que merece destaque é a empolgação manifestada pela maior parte dos entrevistados em participar da pesquisa e doar as sementes para o banco ativo de germoplasma. Eles expressaram ter consciência de que o banco ativo de germoplasma é um reservatório de sementes, onde suas sementes ficam protegidas e, no caso de acontecer a perda da semente por parte do guardião, ela poderia ser restituída. Aconteceram dois casos de restituição de sementes de variedades crioulas de abóbora ornamental para os agricultores, as quais tinham sido doadas para o Banco Ativo de Germoplasma de Cucurbitáceas da Embrapa Clima Temperado. Os doadores haviam perdido suas próprias seleções devido a problemas climáticos. Um caso ocorreu no município de São Lourenço do Sul, na localidade de Reserva, com a Sra. I.F.H. (58 anos), que tinha doado duas variedades de abóboras ornamentais e que perdeu suas sementes em uma grande enchente ocorrida em janeiro de 2009. O outro caso aconteceu no município de Pelotas, na localidade de Cerrito Alegre, com a Sra. I.W. (54 anos), que havia doado uma variedade de abóbora ornamental e que perdeu suas sementes devido à estiagem. Estas duas senhoras ficaram muito felizes de reaverem suas sementes, e assim retomarem o cultivo dessas estimadas variedades. Nas palavras da Sra. I.W. (54 anos): "Esta é uma emoção muito grande! Eu tinha ficado muito triste com a perda das sementes, porque o meи pai tinha me dado... Vou cuidar com muito carinho!"

A colheita dos frutos é realizada, pelos entrevistados, quando o pedúnculo seca ou a planta está senescente. A maioria (18 pessoas) não armazena e não pratica nenhum tipo de cura dos frutos, os que o fazem (três pessoas) são os agricultores que comercializam os frutos na feira de hortifrutigranjeiros; eles armazenam os frutos em caixas, em local arejado, no galpão. O restante dos entrevistados usa os frutos, logo após a colheita, para ornamentação da residência (cozinha ou sala).

Duas entrevistadas comentaram que utilizam suas variedades de abóbora para ornamentar a árvore de Natal. Uma enfeita com barba-de-pau (Tillandsia usneoides) a base da árvore de Natal e coloca as abóboras ornamentais (bicolo- 
res - verde e amarelo) sobre a barba-de-pau, fazendo um arranjo. A outra utiliza frutos desidratados pintados com tinta spray, contendo um furo no pescoço, feito com o auxílio de furadeira, por onde passa uma fita para pendurar os frutos na árvore de Natal. As duas entrevistadas cultivam uma variedade crioula que é conhecida como poronguinho (Cucurbita pepo), pois depois de seco o fruto se parece com um porongo (Lagenaria siceraria).

Outra entrevistada mantém uma variedade crioula de abóbora ornamental denominada de abóbora-ovo (Cucurbita pepo), Figura 2B, por sua semelhança com um ovo de galinha. Além do uso ornamental, o fruto é usado ainda como ovo "indês", para simular a presença de um ovo no ninho de galinha, o que estimula a postura de novos ovos.

Os entrevistados ressaltaram que a polpa da maior parte dos frutos dessas variedades crioulas de abóboras ornamentais é muito amarga, por isso, estas não são indicadas para a alimentação, dado concordante com as informações apresentadas por Heiden et al. (2007). Porém, uma das entrevistadas disse que aproveita os frutos de poronguinho (Cucurbita pepo), Figura 2A, e de abóbora-ovo (Cucurbita pepo), Figura 2B, para alimentação, deixando-os de molho em água com açúcar durante uma noite e cozinhando no dia seguinte. Algumas variedades denominadas de abóbora-estrela (Cucurbita pepo), Figura $2 \mathrm{C}$, além de ornamentais, têm polpa comestível, sendo utilizadas para fazer sobremesas, ficando com uma textura semelhante a do coco ralado. A abóbora cogumela (Cucurbita maxima), Figura 2D, também é utilizada para alimentação, doce ou salgada, além de seu uso ornamental.

Apenas três entrevistados cultivam as variedades ornamentais para vender na feira de hortifrutigranjeiros, dois em Pelotas e um em São Lourenço do Sul. Os demais entrevistados (18) plantam para consumo próprio e para presentear os frutos a parentes e amigos.

Existe grande diversidade de variedades crioulas de abóboras ornamentais mantidas por agricultores familiares do Sul do Rio Grande do Sul. O manejo realizado por estes agricultores no cultivo das abóboras ornamentais é bastante rústico e normalmente realizado pelas mulheres. Os guardiões das sementes crioulas realizam suas próprias seleções de acordo com a característica de fruto que lhe chama mais atenção. Esse procedimento é importante para a manutenção da diversidade genética de abóboras ornamentais em cultivo. Existe uma relação afetiva dos guardiões com suas seleções, as quais consideram como plantas de estimação.

\section{AGRADECIMENTOS}

Aos agricultores guardiões das sementes de variedades crioulas pela disponibilidade e amabilidade na participação das entrevistas. À CAPES (Coordenação de Aperfeiçoamento de Nível Superior), pela bolsa de doutorado cedida ao primeiro autor.

\section{REFERÊNCIAS}

AMOROZO, MCM. 1996. A abordagem etnobotânica na pesquisa de plantas medicinais. In: DI STASI, LC. (org). Plantas medicinais: arte e ciência, um guia de estudo interdisciplinar. São Paulo: EDUSP. p. 47-68.

AMOROZO, MCM; MING, LC; SILVA, SP. 2002. Métodos de coleta e análise de dados em etnobiologia, etnoecologia e disciplinas correlatas. Rio Claro: SBEE. 204p.

BAILEY, K. 1994. Methods of social research. New York: The Free Press. 578p.

BARBIERI, RL. 2012, 02 de março. A diversidade de abóboras no Brasil e sua relação histórica com a cultura. Disponível em: http://www. slowfoodbrasil.com/textos/alimentacao-ecultura/501-aboboras-e-cultura.

BARBIERI, RL; HEIDEN, G; NEITZKE, RS; GARRASTAZÚ, MC; SCHWENGBER, JE. 2006. Banco Ativo de Germoplasma de Cucurbitáceas da Embrapa Clima Temperado - periodo de 2002 a 2006. Pelotas: Embrapa Clima Temperado. 21p.

BEGOSSI, A; HANAZAKI, N; SILVANO, RAM. 2002. Ecologia humana, etnoecologia e conservação. In: AMOROZO, MCM; MING, LC; SILVA, SMP (org). Métodos de coleta e análise de dados em etnobiologia, etnoecologia e disciplinas correlatas. Rio Claro: UNESP/CNPq. p.93-128.
FALEIRO, FG; NETO, ALF; JUNIOR, WQR. 2008. Pré-melhoramento, melhoramento, pós-melhoramento: estratégias e desafios. Planaltina: Embrapa. 183p.

FERREIRA, MAJF. 2008. Abóboras e Morangas: das Américas para o mundo. In: Barbieri, RB; STUMPF, ERT (ed). Origem e evolução de plantas cultivadas. Brasília: Embrapa Informação Tecnológica. 909p.

GALLUZZI, G; EYZAGUIRRI, P; NEGRI, V. 2009. Uncovering European home gardens: their human and biological features and potential contribution to the conservation of agro-biodiversity. In: BAILEY, A; EYZAGUIRRI, P; MAGGIONI, L. Crop genetic resources in European home gardens. Rome: Bioversity International. p. 8-17.

HEIDEN, G; BARBIERI, RL; NEITZKE, RS. 2007. Chave para identificação das espécies de abóboras (Cucurbita, Cucurbitaceae) cultivadas no Brasil. Pelotas: Embrapa Clima Temperado. 31p.

HILLIER, M. 1996. Arranjos de flores secas: guia para cultivo, secagem e apresentação. Londres: Dorling Kindersley. 160p.

HILLIER, M. 2001. Blumen: Kreative arrangements für das ganze Jahr. München: Dorling Kindersley. 515p.

KUMAR, BM; NAIR, PR. 2004. The enigma of tropical homegardens. Agroforestry Systems 61: 135-152.

MING, LC; HIDALGO, AF; SILVA, MAS; SILVA, SMP; CHAVES, FCM. 2000. Espécies brasileiras com potencial alimentar: uso atual e desafios. In: CAVALCANTI, TB (org). Tópicos atuais em botânicas: Palestras convidadas do $51^{\circ}$ Congresso Nacional de Botânica. Brasília: EMBRAPA. p. 268-273.

NAHOUM, P. 2010. Introdução em cultivo, propagação e utilização no paisagismo contemporâneo de plantas nativas da flora brasileira. In: CONGRESSO BRASILEIRO DE RECURSOS GENÉTICOS. Palestras... Salvador (CD-ROM).

NICHOLS, P. 1991. Social survey methods: a field-guide for development workers. Oxford: Oxfam Publishing. 132p.

NUEZ, F; RUIZ, JJ; VALCÁRCEL, JV; CÓRDOVA, PF. 2000. Colección de semillas de calabaza del centro de conservación y mejora de la agrodiversidad valenciana. Madrid: Instituto Nacional de Investigación y Tecnología Agrária y Alimentaria. Ministério de Ciencia Y Tecnologia. 158p.

OAKLEY, E. 2004. Quintais Domésticos: uma responsabilidade cultural. Agriculturas 1: p. 37-39.

PARIS, HS; DAUNAY, MC; PITRA, M; JANICK, J. 2006. First known image of Cucurbita in Europe, 1503-1508. Annals of Botany 98: 41-47.

RAMOS, SRR; QUEIROZ, MA. 2005. Recursos genéticos de abóbora no Nordeste brasileiro. In: LIMA, MC (ed). Recursos genéticos de hortaliças: riquezas naturais. São Luís: Instituto Interamericano de Cooperação para a Agricultura. p. 99-116. 